OPEN ACCESS

Edited by:

Frederick Robert Carrick, Bedfordshire Centre for Mental Health Research in Association with University of Cambridge, United Kingdom

Reviewed by: Cihad Dundar, Ondokuz Mayıs University, Turkey Sandrine Rossi, University of Caen Normandy, France

*Correspondence: Carla Sogos carla.sogos@uniroma1.it

Specialty section:

This article was submitted

to Child Health and

Human Development,

a section of the journal

Frontiers in Pediatrics

Received: 18 June 2017 Accepted: 09 August 2017 Published: 29 August 2017

Citation: Catino E, Di Trani M, Giovannone F, Manti F, Nunziata L, Piccari F, Sirchia V, Vannucci $L$ and Sogos $C$ (2017) Screening for Developmental

Disorders in 3- and 4-Year-Old Italian Children: A Preliminary Study.

Front. Pediatr. 5:181.

doi: 10.3389/fped.2017.00181

\section{Screening for Developmental Disorders in 3- and 4-Year-Old Italian Children: A Preliminary Study}

\author{
Elena Catino ${ }^{1}$, Michela Di Trani'2, Federica Giovannone', Filippo Manti', Letizia Nunziata', \\ Francesca Piccari', Virginia Sirchia', Lucia Vannucci' and Carla Sogos ${ }^{1 *}$ \\ ${ }^{1}$ Department of Child Neurology and Psychiatry, Sapienza Università di Roma, Rome, Italy, ${ }^{2}$ Department of Dynamic and \\ Clinical Psychology, Sapienza Università di Roma, Rome, Italy
}

Background: The "Osserviamo" project, coordinated by the Municipality of Rome and the Department of Pediatrics and Child Neuropsychiatry of Sapienza University, aimed to validate an Italian version of the Ages and Stages Questionnaire-3 and to collect, for the first time in Italy, data on developmental disorders in a sample of 4,000 children aged 3 and 4 years. The present paper presents the preliminary results of the "Osserviamo" project.

Methods: 600 parents of children between 39 and 50 months of age (divided in two age stages: 42 and 48 months) were contacted from 15 kindergarden schools.

Results: $23.35 \%$ of the whole sample scored in the risk range of at least one developmental area of the Ages and Stages Questionnaire-3rd Edition (ASQ-3) and 7.78\% scored in the clinical range. Specifically, $23.97 \%$ of the children in the 42 -month age stage scored in the risk range and $5.79 \%$ scored in the clinical range. Males scored lower than females in the fine motor skills and personal-social development domains. Moreover, $22.79 \%$ of the children in the 48 -month age stage scored in the risk range, while $9.55 \%$ scored in the clinical range. Males scored lower than females in fine motor skills.

Conclusion: Italian validation of the ASQ-3 and recruitment of all 4,000 participants will allow these data on the distribution of developmental disorders to be extended to the general Italian pediatric population. One main limitation of the study is the lack of clinical confirmation of the data yielded by the screening programme, which the authors aim to obtain in later stages of the study.

\section{Keywords: children, screening, neurodevelopmental disorders, mental health, epidemiology}

\section{INTRODUCTION}

Developmental disorders encompass a broad spectrum of disabilities, which are characterized by difficulties with language and speech, motor skills, behavior, memory, learning, and other neurological functions. These disorders are likely to result from a combination of genetic, biological, psychosocial, and environmental risk factors (1).

Early identification of developmental disorders is crucial to children well-being and to provide appropriate therapies and education (2). 
Recent studies suggest periodic developmental surveillance, screening, evaluation, and re-evaluation throughout childhood $(3,4)$ including the Parental Evaluation of Developmental Status (5). Nevertheless, the most effective way to identify children with developmental disorders remains elusive $(6,7)$.

The American Academy of Pediatrics (8) recommends the screenings at different age stages and according to different aims: during the first year of life of the child, paying particular attention to postpartum depression in mothers; at 9, 18, and 24 or 30 months of age, for the early identification of developmental disorders; at 18 and 24 months, for the early identification of autism; at 4 years, to investigate the prerequisites for access to preschool; from 5 years, to evaluate mental health and psychosocial functioning.

Several epidemiological studies have evaluated the rate of developmental disorders, though the results of such studies have proved to be somewhat varied.

In the USA, for instance, studies have reported that $12-16 \%$ of children suffer from developmental disorders $(6,9,10)$. By contrast, studies conducted in other countries (such as Peru, Malaysia, the Netherlands, Norway, Korea) have reported that these problems affect $5-10 \%$ of the pediatric population (11-17). Mackrides and Ryherd (18) reported that the number of children under 5 years of age that display a developmental disorder ranges from 2 to $16 \%$, and that approximately half of these receive a late diagnosis. Other studies have reported that between 4 and $10 \%$ of children in the general population have developmental disabilities, though only $30 \%$ of these are identified before primary school $(19,20)$. A recent study (21) in Denmark reported a 1/186 ratio of subjects with relative risk of autism spectrum disorders (ASDs) in the general population. No data are available on developmental disorders in the general pediatric population for Italy. Data on the prevalence of developmental disorders in the clinical population (from local mental health services for outpatients in the Emilia Romagna region) yielded percentages of $7.79 \%$ for cognitive disability, of $3.04 \%$ for ASDs, of $17.39 \%$ for language delay, and of $1.53 \%$ for developmental coordination disorder (22).

Another study carried out in the Piemonte region ${ }^{1}$ yielded a percentage of $4.81 \%$ for developmental disorders in the overall patient population in neuropsychiatry services. Moreover, the first Italian data that have been released on the prevalence of ASD by the Piemonte, Veneto, and Emilia Romagna regions indicate that the percentage of children with ASD ranges from 1.8 to $3.1 \%$ in a population aged from 1 to 18 years. $^{2}$

\section{The "Osserviamo" Project}

On the basis of these considerations, the Rome Municipality and the Department of Pediatrics and Child Neuropsychiatry at Sapienza University of Rome are coordinating the "Osserviamo" project. The project has three objectives: to validate a tool on the Italian population for the screening of developmental disorders; to collect a first set of epidemiological data on the early

${ }^{1}$ www.sinpia.eu/atom/allegato/1052.pdf.

${ }^{2}$ www.epicentro.iss.it. identification and prevention of developmental disorders in a group of 3- to 4-year-old children; and to create a network of collaboration between parents, kindergarten, and neuropsychiatry services. Data are being collected by Ages and Stages Questionnaire-3rd Edition (ASQ-3), a self-report questionnaire that had demonstrated good psychometric properties for the general pediatric population (9). The aim of the project is to collect data from 4,000 subjects over a 5-year period starting from 2012 (about 800 for each year), which means that the data collection is still in progress. We decided to focus on 3- to 4-year-old children because several conditions of delayed or mild disability may not be evident at early age and may emerge when a child is confronted with more demanding developmental challenges, such as the start of kindergarten.

\section{Objectives of this Paper}

In this paper, we present the preliminary data from the first year of implementation of the "Osserviamo" project. Specifically the aims of the present work were:

1. To verify the appropriateness of the method adopted, and in particular of the sample recruitment method and of the selfreport measure administered to parents. In other screening studies $(4,23)$ samples were recruited by pediatric health care professionals, whereas in the "Osserviamo" project the sample was recruited from schools. Since children in Italy usually start kindergarten at 3 years of age, the authors hypothesized that the recruitment of children in schools would allow a representative sample of the entire pediatric population in this age group to be contacted. We calculated what percentage of the sample contacted agreed to participate in the study. Moreover, parents were asked to complete a self-report questionnaire on developmental delay: the percentage of correctly completed questionnaires was also calculated.

2. To analyze a first data set resulting from the screening observation (600 subjects). As no Italian validation of the ASQ-3 is yet available, our results are based on the American validation cutoff scores of the tool. With regard to this point, the authors specifically aimed to:

- observe the distribution of ASQ-3 scores and the percentages of children identified as "not at risk," "at risk" and "clinical" by the ASQ-3 scores (in different domains of the ASQ-3), according to gender and age groups;

- evaluate differences between males and females in the different domains of the ASQ, separately for the two age groups;

- evaluate false positives through a clinical evaluation of the children whose score fell within the clinical range in at least one ASQ-3 domain.

\section{MATERIALS AND METHODS}

\section{Sample Selection}

During the first year of implementation of the study (2012), a sample of 600 children aged from 39 to 50 months was identified in 15 kindergarten schools of Rome (one for each sub-municipality 
of Rome). The schools and the number of children for each school were selected according to the most recent population census, conducted in Rome in 2011, which provided information on the number of inhabitants in each of the 15 sub-municipalities of Rome and the number of children in each school in the submunicipalities (24). A representative sample of children (proportionate to the number of children living in each sub-municipality) aged between 39 and 50 months (i.e., attending the first year of kindergarten) was randomly selected in each of these schools, thus ensuring that the sample was composed of children from all the sub-municipalities. This method does not, however, guarantee that all the socioeconomic levels were represented equally. This variable will be controlled more systematically in the subsequent stages of the Osserviamo project than was possible in this first step of the study.

\section{Procedure}

Once we had identified the sample, we obtained authorization from the school districts to contact the schools' principals. Three meetings with the schools' principals and the teachers' coordinators were held to explain what developmental disorders are, as well as the aims and the methodology of the Osserviamo project. All of the principals agreed to the project and consequently allowed us to contact the children's parents through the teachers' coordinators, who ensured that the questionnaire was sent to and returned by the parents. Informed consent was obtained from the parents of children who agreed to participate in the study. We requested an e-mail address or telephone number to be able to contact them again. All the parents were informed that the information collected would be confidential and that participation in the study was exclusively on a voluntary basis. A dedicated telephone number was also set up so as to answer any questions the parents wished to ask about the Osserviamo project. The parents were then asked to complete the Ages and Stages Questionnaire-3 (see Assessment). All the data were collected in the school year 2011-2012.

In a second step, the parents of children who fell within the clinical range in one, or more than one, domain of the ASQ-3 were contacted by email or telephone by a clinician of the neuropsychiatric services, who suggested that a meeting be arranged to discuss the ASQ-3 data. This first observation was followed, if deemed necessary, by a comprehensive neuropsychiatric evaluation (cognitive, neuropsychological, and psychopathological) of the child, during which the disorder was either confirmed or not confirmed. Children were thus offered the opportunity to promptly start targeted treatment that involved both the parents and schools directly.

\section{Assessment}

The authors used the 42 -month (from 39 to 45 months) and the 48-month (from 45 to 51 months) forms of the Ages and Stages Questionnaire-3rd Edition (ASQ-3).

The ASQ-3 is a screening tool used to assess development during the first 5 years of life (20). It consists of 21 questionnaires to be used on children of $2,4,6,8,9,10,12,14,16,18,20,22,24$, $27,30,33,36,42,48,54$, and 60 months of age. The questionnaires have 30 developmental items divided into five domains: communication, gross motor, fine motor, problem solving, and personal-social development. The questionnaire must be completed by the parent or the caregiver of the child. Answers to items are rated yes, sometimes, or not yet and are scored as 10, 5, or 0, respectively. Each questionnaire is administered to the children of that age and in the \pm 1 -month range. As the questionnaires cover wider age ranges after 27 months, administration of two successive forms is recommended for children who are outside the \pm 1 -month range (20). Domain cutoff scores were calculated on the basis of 2 SD. It was suggested that children whose questionnaire results stood at, or below, the established cutoff score in one or more of the domains should be referred for further assessment.

Several reports indicate that the ASQ-3 has well-established psychometric properties in a clinical context, such as test-retest reliability, internal consistency, criterion validity, sensitivity, and specificity $(20,25-28)$. The validity of the ASQ-3 tested on 18,000 questionnaires administered in the United States yielded an overall agreement across questionnaires of $86 \%$, with a range of $73-100 \%$. Sensitivity (i.e., children in whom the ASQ detected a developmental delay and who had a delay according to the standardized assessment) ranged from 85 to $92 \%$, while specificity (i.e., children in whom the ASQ-3 did not detect a delay and whose development was normal according to the standardized assessment) ranged from 78 to $92 \%$. Validity and reliability ranged from 70 to $100 \%(25-28)$.

In the present study, since an Italian version of the ASQ is not available, the questionnaire was translated from English into Italian and, subsequently, to verify any language inaccuracies, it was back translated into the original language. A pilot administration to 20 parents permitted some cultural and lingual adaptations. The final version was therefore included in the study.

\section{Data Analysis}

In order to evaluate the sample recruitment method and the use of the self-report measure administered to parents, we calculated the percentage of the sample who agreed to participate in the study and who completed the questionnaires correctly.

In order to analyze a first set of data yielded by the screening program, we calculated the distribution of the scores as well as the percentages of children identified as being "not at risk," "at risk," and "clinical," according to gender and across age stages, on the basis of the USA cutoff values. A series of Student's $t$-test were used to compare the scores of the gender groups (boys vs girls) on different ASQ-3 domains, and a Chi ${ }^{2}$ test was performed to verify difference between the two age stages on the prevalence of subjects with a score in the clinical range. The clinical diagnosis made in the children who fell within the clinical range of the ASQ-3, and consequently underwent a neuropsychiatric evaluation, was provided, as was the percentage of false positive of the ASQ-3.

The data were analyzed by means of the SPSS program.

\section{RESULTS}

Data were collected from 532 out of a total of 600 children ( $88.67 \%$ of the sample agreed to participate) and were 
analyzed in 514 children $(3.38 \%$ of the questionnaires were not answered correctly). The reasons for why parents refused to participate are unknown as the authors were unable to contact them.

The whole sample was divided into two age stages: $39-45$ months (242 subjects; 123 boys and 119 girls; age mean $=42.65$; SD $=1.82$ ) and $45-51$ months (272 subjects; 147 boys, 125 girls; age mean $=48.08 ; \mathrm{SD}=2.62$ ).

Table 1 shows the mean values and SD for each ASQ-3 domain for the whole sample divided according to age stages for both the Italian and USA studies, and divided according to gender for the Italian sample alone. From a qualitative point of view, the means of the Italian sample were higher than those of the USA sample, while the Italian SDs were lower than the USA SDs, in each ASQ-3 domain and for both the 42- and 48-month age stages. As regard the 42 -month age stage, Student's $t$-tests between gender groups revealed significant differences in fine motor skills $(t=-2.91$; $p=0.002$; degrees of freedom $=240$; boys mean $=52.83$, $\mathrm{SD}=9.16$; girls mean $=56.26, \mathrm{SD}=7.60)$ and personal-social development $(t=-2.41 ; p=0.02$; degrees of freedom $=240$; boys mean $=50.70, \mathrm{SD}=8.01$; girls mean $=53.28, \mathrm{SD}=7.85$ ). In particular, boy scores were lower than girl scores in both domains. As for the 48-month age stage, boy scores were lower than girl scores in fine motor skills alone $(t=-3.50 ; p=0.002$; degrees of freedom $=270$; boys mean $=50.34, \mathrm{SD}=11.52$; girls mean $=54.92, \mathrm{SD}=7.81$ ).

Overall, 120 children (23.35\% of the total sample of 514 subjects) fell within the risk range of at least one developmental area, while 40 children $(7.78 \%)$ fell within the clinical range according to the ASQ. In particular, in the 42-month age stage, 58 children (23.97\% of 242 subjects) fell within the risk range and 14 (5.79\%) within the clinical range, whereas in the 48-month age stage, 62 children (22.79\% of 272 subjects) fell within the risk range and 26 (9.55\%) within the clinical range. As regard the clinical range, the difference between the two age stages on the prevalence of the disorders (5.79\% in the 42 -month age stage vs $9.55 \%$ in the 48-month age stage) was not statistically significant.

Tables $\mathbf{2}$ and $\mathbf{3}$ show the children's developmental status for the 42- and 48-month age stages for the sample taken as a whole and divided according to gender group.

As regard the clinical evaluations, 9 children in the 42-month age stage (out of a total of 14 children who fell within the clinical range) and 15 children in the 48-month age stage (out of a total of 26 children who fell within the clinical range) underwent a neuropsychiatric evaluation and thus received a clinical diagnosis. Sixteen parents refused the clinical evaluation: 12 of these parents ( 4 from the 42-month age stage and 8 from the 48 -month age stage) did not agree to the

TABLE 1 | Means and SD for each Ages and Stages Questionnaire-3rd Edition (ASQ) domain, for the USA and Italian samples, separately for 42- and 48-month age stages.

\begin{tabular}{|c|c|c|c|c|c|}
\hline & Communication & Gross motor & Fine motor & Problem solving & Personal-social development \\
\hline \multicolumn{6}{|c|}{ ASQ age stage: 42 months } \\
\hline \multicolumn{6}{|c|}{ Total USA sample, $n=956$} \\
\hline Mean & 50.02 & 54.03 & 47.55 & 51.54 & 51.39 \\
\hline SD & 11.48 & 8.88 & 13.87 & 11.72 & 10.13 \\
\hline \multicolumn{6}{|c|}{ Total Italian sample, $n=242$} \\
\hline Mean & 57.00 & 56.82 & 54.42 & 56.49 & 51.92 \\
\hline SD & 6.59 & 6.01 & 8.71 & 6.67 & 8.04 \\
\hline \multicolumn{6}{|c|}{ Italian boys, $n=123$} \\
\hline Mean & 56.76 & 56.27 & 52.83 & 56.15 & 50.70 \\
\hline SD & 5.89 & 6.51 & 9.16 & 5.74 & 8.01 \\
\hline \multicolumn{6}{|c|}{ Italian girls, $n=119$} \\
\hline Mean & 57.23 & 57.35 & 56.26 & 56.81 & 53.28 \\
\hline SD & 7.27 & 5.44 & 7.60 & 7.53 & 7.85 \\
\hline \multicolumn{6}{|c|}{ ASQ age stage: 48 months } \\
\hline \multicolumn{6}{|c|}{ Total USA sample, $n=672$} \\
\hline Mean & 52.92 & 52.71 & 45.35 & 52.78 & 50.34 \\
\hline SD & 11.10 & 9.97 & 14.77 & 10.74 & 11.87 \\
\hline \multicolumn{6}{|c|}{ Total Italian sample, $n=272$} \\
\hline Mean & 56.65 & 54.03 & 52.39 & 54.82 & 51.60 \\
\hline SD & 6.34 & 8.42 & 10.25 & 7.79 & 8.25 \\
\hline \multicolumn{6}{|c|}{ Italian boys, $n=147$} \\
\hline Mean & 56.12 & 54.66 & 50.34 & 54.18 & 50.75 \\
\hline $\mathrm{SD}$ & 6.99 & 7.76 & 11.52 & 7.50 & 8.20 \\
\hline \multicolumn{6}{|c|}{ Italian girls, $n=125$} \\
\hline Mean & 57.34 & 53.27 & 54.92 & 55.65 & 52.62 \\
\hline SD & 5.43 & 9.15 & 7.81 & 8.06 & 8.25 \\
\hline
\end{tabular}

Note: means and SD for the USA samples were derived from Squires et al. (20). 
TABLE 2 | Children's developmental status in the 42-month age stage, for the whole sample and according to gender group.

\section{Developmental status}

\begin{tabular}{|c|c|c|c|}
\hline & Not at risk, $n(\%)$ & At risk, $n(\%)$ & Clinical, $\boldsymbol{n}(\%)$ \\
\hline \multicolumn{4}{|l|}{ Communication } \\
\hline Total sample, $N=242$ & $236(97.5)$ & $5(2.1)$ & $1(0.4)$ \\
\hline Boys, $N=123$ & $120(97.6)$ & $3(2.4)$ & / \\
\hline Girls, $N=119$ & $116(97.5)$ & $2(1.7)$ & $1(0.8)$ \\
\hline \multicolumn{4}{|l|}{ Gross motor } \\
\hline Total sample, $N=242$ & 220 (90.9) & 20 (8.3) & $2(0.8)$ \\
\hline Boys, $N=123$ & 107 (87\%) & $15(12.2 \%)$ & $1(0.8)$ \\
\hline Girls, $N=119$ & $113(95.0)$ & 5 (4.2) & $1(0.8)$ \\
\hline \multicolumn{4}{|l|}{ Fine motor } \\
\hline Total sample, $N=242$ & $234(96.7)$ & $6(2.5)$ & $2(0.8)$ \\
\hline Boys, $N=123$ & $116(94.3)$ & $6(4.9)$ & $1(0.8)$ \\
\hline Girls, $N=119$ & $118(99.2)$ & I & $1(0.8)$ \\
\hline \multicolumn{4}{|l|}{ Problem solving } \\
\hline Total sample, $N=242$ & 233 (96.3) & $7(2.9)$ & $2(0.8)$ \\
\hline Boys, $N=123$ & $117(95.1)$ & $6(4.9)$ & / \\
\hline Girls, $N=119$ & $116(97.5)$ & $1(0.8)$ & $2(1.7)$ \\
\hline \multicolumn{4}{|l|}{ Personal-social skills } \\
\hline Total sample, $N=242$ & $215(88.8)$ & $20(8.3)$ & $7(2.9)$ \\
\hline Boys, $N=123$ & $107(87.0)$ & $12(9.8)$ & $4(3.3)$ \\
\hline Girls, $N=119$ & $108(90.8)$ & $8(6.7)$ & $3(2.5)$ \\
\hline
\end{tabular}

TABLE 3 | Children's developmental status in the 48-month age stage, for the whole sample and according to gender group.

\section{Developmental status}

Not at risk, $\boldsymbol{n}(\%) \quad$ At risk, $\boldsymbol{n}(\%) \quad$ Clinical, $\boldsymbol{n}(\%)$

\section{Communication}

Boys, $N=147$

Girls, $N=125$

Gross motor

Boys, $N=147$

Girls, $N=125$

Fine motor

Total sample, $N=272$

Boys, $N=147$

Girls, $N=125$

\section{Problem solving}

Total sample, $N=272$

Boys, $N=147$

Girls, $N=125$

Personal-social skills

Total sample, $N=272$

Boys, $N=147$

Girls, $N=125$

\begin{tabular}{|c|c|c|}
\hline 259 (95.2) & $10(3.7)$ & $3(1.1)$ \\
\hline 138 (93.9) & $7(4.8)$ & $2(1.4)$ \\
\hline 121 (96.8) & $3(2.4)$ & $1(0.8)$ \\
\hline 245 (90.1) & $18(6.6)$ & 8 (2.9) \\
\hline 136 (92.5) & $8(5.4)$ & $3(2.0)$ \\
\hline $110(88.0)$ & $10(8.0)$ & $5(4.0)$ \\
\hline 256 (94.1) & $12(4.4)$ & $4(1.5)$ \\
\hline 134 (91.2) & $10(6.8)$ & $3(2.0)$ \\
\hline 122 (97.6) & 2 (1.6) & $1(0.8)$ \\
\hline 253 (93.0) & $11(4.0)$ & $8(2.9)$ \\
\hline 134 (91.2) & $9(6.1)$ & $4(2.7)$ \\
\hline 119 (95.2) & $2(1.6)$ & $4(3.2)$ \\
\hline 257 (94.5) & $11(4.0)$ & $3(1.1)$ \\
\hline 137 (93.2) & $8(5.4)$ & $2(1.4)$ \\
\hline 121 (96.8) & $3(2.4)$ & $1(0.8)$ \\
\hline
\end{tabular}

clinical evaluation because their children had already received a diagnosis and were being treated in other services, whereas the remaining 4 did not provide any reason for their refusal. As regard children who had already received a diagnosis, 3 in the 42 -month age stage were diagnosed with a Language
Disorder and 1 with a Language Disorder and a comorbid Developmental Coordination Disorder; 7 in the 48-month age stage were diagnosed with a Language Disorder and 1 with global developmental immaturity.

In the 42-month age stage sample, 1 child was diagnosed with ASD, 5 children with a Language Disorder, 2 children with a Developmental Coordination Disorder, while no diagnosis was made in 1 child; in the 48 -month age stage sample, 1 child was diagnosed with ASD, 2 children with a Language Disorder, 4 children with a Developmental Coordination Disorder, 2 children with a Intellectual Disability, 1 child with a Developmental Coordination Disorder plus Intellectual Disability, 3 children with a Language Disorder plus Developmental Coordination Disorder, while non-diagnosis was made in 2 children.

In conclusion, 3 children (out a total of 24 children evaluated, $12.50 \%$ ) who fell within the clinical range of the ASQ-3 did not receive a diagnosis (false positive); all 3 of these children displayed a range of difficulties and developmental immaturity.

\section{DISCUSSION}

The first objective of this study was to assess whether the methods adopted to recruit the sample of the screening program were adequate, and whether the school context provided favorable recruitment conditions for the study.

Another reason for the choice is that the recruitment of children through schools helps to create a direct relationship between parents and the school and neuropsychiatric services, thereby providing support to parents and teachers as well as direct access to these services when required. The data yielded by the present study on this aspect of the program confirm not only that the school system responded actively to the project (no school principal refused to cooperate), but also that a large proportion of the parents participated in the study, completing the questionnaire and returning it to the school: $88.67 \%$ (532 out of a total of 600) adhered to the screening program. This figure is in keeping with those reported by other screening programs in the literature (29). In this regard, since participation in screening programs is voluntary, a certain amount of non-adherence is to be expected (30).

A second issue that the authors investigated regarding the screening methodology was the feasibility of distributing a questionnaire to be completed by parents at home, with no direct support from a specialist. In this preliminary phase of the study, only $3.38 \%$ of the questionnaires ( 18 out of 532 ) could not be used because they had been completed incorrectly. The authors may therefore conclude that the collection of information by asking participants to complete the ASQ-3, according to instructions given to parents in writing by teachers, was effective. In addition, the low proportion of incorrectly completed questionnaires indirectly confirms that the questionnaire was relatively easy to complete and that it allowed, by investigating the children's skills in daily life, parents to conduct a guided observation of their children's behavior and of their development stage. This tool can thus be easily used by both families and teachers.

Another objective of the pilot project was to analyze the preliminary screening data. Before addressing this topic, it is necessary to once again point out that no normative data for the 
ASQ-3 exist for the Italian population (obtaining such data is one of the general objectives of the "Osserviamo" project). This means that these preliminary data are based on guidelines drawn up according to the validation of the tool in the USA.

One aspect that deserves consideration is that regarding the averages and the SD of the US and Italian samples. A substantial overlap emerged between the average values in the age groups considered, although the values in the Italian sample are always higher than those in the US sample. The Italian values are actually closer to those yielded by other validations of the ASQ-3 [for example, in Korean and Norway (17)] than to the American values. As regard the $\mathrm{SD}$, however, the Italian values appear to be qualitatively lower than those of the US. This becomes even more significant since the cutoff for being defined either "at risk" or "clinical" is based on the rule of the mean minus 1 or 2 SD; the cutoff used to define the risk and clinical areas in the selected sample is consequently strongly dependent on these values. According to the formula used to define the cutoff, if a lower SD were to persist even when the size of the Italian sample increases, the authors could assume that the Italian cut-off values need to be lower than the US cutoff values. This would alter the results regarding the frequency of "at risk" and "clinical" children in the study population in this preliminary phase of the study (in the 42-month range, $24 \%$ of the sample falls within the risk range, and about $6 \%$ in the clinical range, whereas in the of 48 -month range, about $23 \%$ of the sample falls within the risk range, and about $10 \%$ in the clinical range) since the adoption of the US cutoff may have led to the phenomenon being underestimated in the Italian population.

Moreover, with regard to gender differences, which are obtained by comparing the average boy and girl scores and are therefore not likely to be affected by the use of the US cutoff, girl scores were significantly higher than those of boys (with the former consequently appearing to be more competent) in fine motor skills and in personal-social skills in the 42-month range as well as in fine motor skills in the 48-month range. These data are in keeping with those reported in other studies based on the ASQ-3 (e.g., Brazilian), in which girl subjects achieved higher scores than boys $(31,32)$. These results also reflect the findings which indicate that girls from different cultural backgrounds in the preschool age group achieve higher scores in all areas except gross motor skills (30). The fact that the results yielded by this preliminary screening program are in keeping with those of other study points to the validity of the adopted tool (30-35).

As regard the clinical evaluations, the parents of 24 (out of a total of 40) of the children who fell within the clinical range at the ASQ-3 agreed to the clinical evaluation. Some of the parents who refused did not agree the clinical evaluation because their children had already received a diagnosis and were being treated in other services, whereas others did not provide any reason for their refusal. The fact that the most frequent disorder in children in whom a diagnosis has already been made is the language disorder (10 children out of a total of 12) is likely to be due language difficulties being more easily recognized than other difficulties by adults, who then seek help. Some of these children scored in the clinical range in other ASQ-3 domains, such as in the personal-social skill; it is possible that children being treated for language difficulties are perceived by their parents as being less skillful on the social level than on the language level because the children's language level is currently closer to normal, or perceived as being closer to normal, than their social level as a result of the therapy.

The children who were evaluated and received a neurodevelopmental diagnosis accounted for $87.50 \%$ of the sample $(12.50 \%$ of false positives). Preliminary data on specificity of the ASQ-3 indicate that the trend is good, though no statistical analysis can be performed yet owing to the small sample size. As regard the clinical diagnosis, 2 children were diagnosed with ASD; the identification of these two children between 42 and 48 months of age with undiagnosed autism and the prompt activation of support for the children, families, and teachers is highly relevant to the children's future development. Moreover, language disorders were predominant in the 42 -month age stage ( 5 children out of a total of 9), whereas they decreased (2 children out of a total of 15) in the 48-month age stage or occurred in comorbidity with other disorders, such as the developmental coordination disorder. Overall, language difficulties appear to be more visible to a child's parents, whereas coordination disturbances escape recognition more often and are consequently diagnosed less often as a result of parental reports.

One of the main limitations of this study was the use of normative data taken from the US validation of the questionnaire. Indeed, our data were analyzed using the US cutoff values, which were drawn up for a very different population in terms of composition, sociodemographic characteristics and cultural activities. The potential bias due to the use of this tool may be even greater since the etiology of developmental disorder is multifactorial and depends on environmental and genetic factors that impact in different ways on a child's phenotype. Although the authors were obliged to use this cutoff value in the preliminary phase of the data analysis, calibration of the tool is one of the objectives of the "Osserviamo" project.

Other limitations of the present study are the lack of the clinical confirmation of the data yielded by the screening program, which the authors aim to obtain in later stages of the study, and the fact that the children sample was limited to Rome, which is the only municipality in which funding for data collection was available.

In the future, the "Osserviamo" project, which is an ongoing study, aims to study a larger sample $(N=4,000)$, to validate the ASQ-3 and to perform a clinical study on children defined as being either "at risk" or "clinical" by the screening program.

\section{ETHICS STATEMENT}

The design of the screening was approved by the ethical committee of Department of Dynamic and Clinical Psychology, "Sapienza" University of Rome, Italy.

\section{AUTHOR CONTRIBUTIONS}

CS had primary responsibility for protocol development and patient enrollment, supervised the execution of all the phases of the screening, and contributed to the writing of the manuscript. 
EC participated in the development of the protocol and had primary responsibility for patient screening; MT analyzed the data. FG, FM, LN, FP, VS, and LV contributed equally to the screening and interpretation of data. All authors contribute to the writing of the manuscript. All authors read and approved the final version of the manuscript.

\section{REFERENCES}

1. Rutter M, Bishop DVM, Pine DS, Scott S, Stevenson J, Taylor E, et al. Rutter's Child and Adolescent Psychiatry. 5th ed. Malden, Massachussetts: Blackwell Publishing Limited (2008).

2. Ertem IO. Monitoring and supporting child development. 22nd ed. In: Rudolph CD, Rudolph AM, Lister GE, First L, Gershon AA, editors. Rudolph's Pediatrics. Columbus: McGill Hill Professional (2010). 36 p.

3. Bear LM. Early identification of infants at risk for developmental disabilities. Pediatr Clin North Am (2004) 51:685-701. doi:10.1016/j.pcl.2004. 01.015

4. Earls MF, Hay SS. Setting the stage for success: implementation of developmental and behavioral screening and surveillance in primary care practice-the North Carolina Assuring Better Child Health and Development (ABCD) Project. Pediatrics (2006) 118:83-188. doi:10.1542/ peds.2006-0475

5. Glascoe FP. Parents' evaluation of developmental status: how well do parents' concerns identify children with behavioral and emotional problems? Clin Pediatr (2003) 42:133-8. doi:10.1177/000992280304200206

6. Rydz D, Srour M, Oskoui M, Marget N, Shiller M, Birnbaum R, et al. Screening for developmental delay in the setting of a community pediatric clinic: a prospective assessment of Parent-Report Questionnaires. Pediatrics (2006) 118:1178-86. doi:10.1542/peds.2006-0466

7. Sices L, Feudtner C, McLaughlin J, Drotar D, Williams M. How do primary care physicians identify young children with developmental delays? A national survey. J Dev Behav Pediatr (2003) 24:409-17. doi:10.1097/ 00004703-200312000-00002

8. Foy JM, Kelleher KJ, Laraque D; American Academy of Pediatrics Task Force on Mental Health. Enhancing pediatric mental health care: strategies for preparing a primary care practice. Pediatrics (2010) 125(Suppl 3):S87-108. doi:10.1542/peds.2010-0788E

9. Squires J, Bricker D, Potter L. Revision of a parent-completed developmental screening tool: Ages and Stages Questionnaires. J Pediatr Psychol (1997) 22:313-28. doi:10.1093/jpepsy/22.3.313

10. Boyle CA, Decouflé P, Yeargin-Allsopp M. Prevalence and health impact of developmental disabilities in US children. Pediatrics (1994) 93:399-403.

11. Oberklaid F, Efron D. Developmental delay - identification and management. Aust Fam Physician (2005) 34:739-42.

12. Officer A, Posarac A. World Report on Disability. Geneva: World Health Organization (2011). Available from: http://www.who.int/disabilities/world_ report/2011/en/index.html

13. Kyerematen V, Hamb A, Oberhelman RA, Cabrera L, Bernabe-Ortiz A, Berry SJ. Exploratory application of the Ages and Stages (ASQ) child development screening test in a low income Peruvian shantytown population. BMJ Open (2014) 4:e004132. doi:10.1136/bmjopen-2013-004132

14. Tan KL, Yadav H. Reassessment on the development of children with disability in Malaysia. Med J Malaysia (2008) 63:17-20.

15. Kerstjens JM, Bos AF, ten Vergert EM, de Meer G, Butcher PR, Reijneveld SA. Support for the global feasibility of the Ages and Stages Questionnaire as developmental screener. Early Hum Dev (2009) 85:443-7. doi:10.1016/j.earlhumdev.2009.03.001

16. Sonnander K. Early identification of children with developmental disabilities. Acta Paediatr Suppl (2000) 89(434):17-23. doi:10.1111/j. 1651-2227.2000.tb03091.x

17. Heo KH, Squires J, Yovanoff P. Cross-cultural adaptation of a pre-school screening instrument: comparison of Korean and US populations. J Intellect Dis Res (2008) 52:195-206. doi:10.1111/j.1365-2788.2007.01000.x

\section{FUNDING}

The "Osserviamo" project is supported by grants from the Rome Municipality-Roma CAPITALE-Dipartimento dei Servizi Educativi e Scolastici, Politiche della Famiglia e dell'Infanzia, Italy.

18. Mackrides PS, Ryherd SJ. Screening for developmental delay. Am Fam Physician (2011) 84:544-9.

19. Maternal Child Health Bureau. The National Survey of Children with Special Health Care Needs: Chartbook 2005-2006 (2008). Available from: https:// webarchive.library.unt.edu/eot2008/20080916005141/http:/mchb.hrsa.gov/ cshcn05/

20. Squires J, Bricker DD, Twonbly E, Potter L. Ages \& Stages Questionnaires: A Parent-Completed Child Monitoring System. 3rd ed. Baltimore: Paul H. Brookes Publishing (2009).

21. Sandin S, Schendel D, Magnusson P, Hultman C, Surèn P, Susser E, et al. Autism risk associated with parental age and with increasing difference in age between the parents. Mol Psychiatry (2016) 21:693-700. doi:10.1038/ mp. 2015.70

22. Stagi P, Vicini S, Mimmi S. Analisi dellutenza afferita al servizio di Neuropsichiatria dell'Infanzia e dell'adolescenza dell'AUSL di Modena nel decennio 2000-2009. Psich Inf Adol (2011) 78:279-91.

23. Godoy L, Carter AS. Identifying and addressing mental health risks and problems in primary care pediatric settings: a model to promote developmental and cultural competence. Am J Orthopsych (2013) 83:73-88. doi:10.1111/ ajop. 12005

24. Istituto Nazionale di Statistica. (2012). Available from: https://www.istat.it/it/ archivio/censimento+popolazione

25. Squires J, Katzev A, Jenkins F. Early screening for developmental delays: use of parent-completed questionnaires in Oregon's Healthy Start Program. Early Child Dev Care (2015) 172:275-82. doi:10.1080/030044302 90030804

26. Vameghi R, Sajedi F, Kraskian Mojembari A, Habiollahi A, Lornezhad HR, Delavar B. Cross-cultural adaptation, validation and standardization of Ages and Stages Questionnaire (ASQ) in Iranian Children. Iran J Publ Health (2013) 42:522-8.

27. Richter J, Janson HA. Validation study of the Norwegian version of the Ages and stages Questionnaires. Acta Paediatr (2007) 96:748-52. doi:10.1111/j.1651-2227.2007.00246.x

28. Kapci EG, Kucuker S, Uslu RI. How applicable are Ages and Stages Questionnaires for use with Turkish children? Topics Early Child Spec Educ (2010) 30:176-88. doi:10.1177/0271121410373149

29. Harris R. Overview of screening: where we are and where we may be headed. Epidemiol Rev (2011) 33:1-6. doi:10.1093/epirev/mxr006

30. Lansdorp-Vogelaar I, Knudsen AB, Brenner H. Cost-effectiveness of colorectal cancer screening. Epidemiol Rev (2011) 33:68-100. doi:10.1093/ epirev/mxr004

31. Filgueiras A, Pires P, Maissonette S, Landeira-Fernandez J. Psychometric properties of the Brazilian-adapted version of the Ages and Stages Questionnaire in public child daycare centers. Early Hum Dev (2013) 89:561-76. doi:10.1016/j.earlhumdev.2013.02.005

32. Limbos MM, Joyce DP. Comparison of the ASQ and PEDS in screening for developmental delay in children presenting for primary care. J Dev Behav Pediatr (2011) 32(7):499-511. doi:10.1097/DBP.0b013e31822552e9

33. Lung FW, Chiang TL, Lin SJ, Feng JY, Chen PF, Shu BC. Gender differences of children's developmental trajectory from 6 to 60 months in the Taiwan Birth Cohort Pilot Study. Res Dev Disabil (2011) 32:100-6. doi:10.1016/j. ridd.2010.09.004

34. Abo El Elella SS, Tawfik MA, Abo El Fotoh WM, Barseem NF. Screening for developmental delay in preschool-aged children using parent-completed Ages and Stages Questionnaires: additional insights into child development. Postgrad Med J (2017). doi:10.1136/postgradmedj-2016134694 
35. Chong KC, Zhou VL, Tarazona D, Tuesta H, Velásquez-Hurtado JE, Sadeghi R, et al. ASQ-3 scores are sensitive to small differences in age in a Peruvian infant population. Child Care Health Dev (2017) 43(4):556-65. doi:10.1111/cch.12469

Conflict of Interest Statement: The authors declare that the research was conducted in the absence of any commercial or financial relationships that could be construed as a potential conflict of interest.
Copyright (c) 2017 Catino, Di Trani, Giovannone, Manti, Nunziata, Piccari, Sirchia, Vannucci and Sogos. This is an open-access article distributed under the terms of the Creative Commons Attribution License (CC BY). The use, distribution or reproduction in other forums is permitted, provided the original author(s) or licensor are credited and that the original publication in this journal is cited, in accordance with accepted academic practice. No use, distribution or reproduction is permitted which does not comply with these terms. 